\title{
Contexto cultural y características de la institución como estrategias de aculturación ${ }^{1}$
}

\author{
Cultural context and characteristics of the institution as acculturation strategies \\ Sandy Elizabeth, Martínez-Lara ${ }^{2}$; Gerardo, Tamez-González ${ }^{3}$; Francisco Anibal, Ganga-Contreras ${ }^{4}$
}

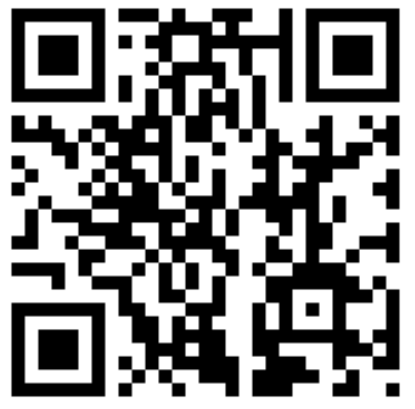

Fecha de recibido: 20-09-2020

Fecha de aceptado: 02-12-2020

\section{(cc) $\mathrm{EY}$-NC-ND}

Esta obra está bajo una licencia de Creative Commons ReconocimientoNoComercial-SinObraDerivada $\quad 4.0$ Internacional

\begin{abstract}
RESUMEN
Este artículo tiene por objetivo determinar la relación entre el contexto cultural y las características de la institución como variables del proceso de aculturación y adaptación cultural en los estudiantes de Educación Superior que realizan una movilidad académica en el extranjero. A través de una metodología mixta con estudios cualitativos y cuantitativos, mediante el uso de entrevistas semiestructuradas a profundidad aplicadas a expertos en temas de internacionalización de la Educación Superior; asimismo fueron aplicadas un total de 43 encuestas a estudiantes que realizaron una movilidad académica durante los años 2016-2017. Los principales resultados arrogaron relaciones importantes entre las variables debido a que el contexto cultural obtuvo un a $=0.741$, mientras que características de la institución $\mathrm{a}=0.813$. Por otra parte, los expertos indican que los estudiantes deben de tener el mayor conocimiento previo posible sobre la cultura e institución del país receptor. Es así como se concluye que el contexto cultural y las características de la institución son factores estratégicos dentro del proceso de aculturación en estudiantes.
\end{abstract}

Palabras claves: Aculturación, características de la institución, contexto cultural.

\begin{abstract}
This article aims to determine the relationship between the cultural context and the characteristics of the institution as variables in the process of acculturation and cultural adaptarion in Higher Education students did an academic mobility abroad. Through a mixed methodology with qualitative and quantitative studies, through the use of semistructured interviews applied to experts on issues of internationalization of Higher Education; likewise, a total of 43 surveys were applied to students who do an academic exchange during the years 2016-2017. The main results showed important relationships between the variables because the cultural context obtained $a=.741$, while characteristics of the institution $\mathrm{a}=.813$. On the other hand, experts indicate that students should have as much previous knowledge about the culture and institution of the host country. This is how it is concluded that the cultural contex $t$ and the characteristics of the institution are strategic factors within the acculturation process in students.
\end{abstract}

Keywords: Acculturation, characteristics of the institution, cultural context.

Cómo referenciar este artículo:

Martínez-Lara., S. E., Tamez-González., G. \& Ganga-Contreras., F. A. (2021). Contexto cultural y características de la institución como estrategias de aculturación. Revista Politica Globalidad y Ciudadanía, 7(14), 1-21. https://doi.org/10.29105/pgc7.14-1

\footnotetext{
${ }^{1}$ Este artículo es producto del proyecto "Factores del proceso de aculturación que facilita el rendimiento académico de los estudiantes de Educación Superior de la Universidad Autónoma de Nuevo León durante su intercambio académico en el extranjero". Iniciado en 2016 y finalizado en 2019.

${ }^{2}$ Doctora en Relaciones Internacionales, Negocios y Diplomacia, Univesidad Autónoma de Nuevo León, Monterrey, México profesor investigador, Facultad de Ciencias Políticas y Relaciones Internacionales. Email: sandy.martinezlr@uanl.edu.mx. Orcid: https://orcid.org/0000-0002-0294-9629

${ }^{3}$ Doctor en Gerencia y Política Educativa Universidad Autónoma de Nuevo León, Monterrey, México profesor titular de tiempo completo, Facultad de Ciencias Políticas y Relaciones Internacionales, Email: gerardo.tamezg@uanl.mx. Orcid: https://orcid.org/0000-0002-2361-0691

${ }^{4}$ Doctor en Administración, Universidad de Tarapacá, Chile profesor investigador, Email: ganga.francisco@gmail.com. Orcid: https://orcid.org/00000001-9325-6459
} 


\section{1.- INTRODUCCIÓN}

Actualmente, para el sector académico la globalización brinda un mayor acceso en los diferentes métodos y formas de estudio entre personas de diferentes naciones, dando como resultado el reto de la internacionalización. Ante esto, la movilidad académica se traduce como aquella actividad de cooperación e intercambio que realiza un estudiante para realizar o continuar sus estudios en una universidad en el extranjero. Asimismo, busca que los estudiantes conozcan y convivan con personas de diferente cultura, cuenten con procesos de enseñanza diferentes y tengan diversas técnicas de aprendizaje, con la finalidad, de que los estudiantes conozcan las costumbres y tradiciones de personas de una cultura distinta a la de ellos; es así como el proceso del intercambio académico brinda múltiples beneficios a los estudiantes.

De acuerdo con, Ward, Bochner y Furnam (2001) afirma que el contacto entre individuos de diversas culturas resulta cada vez más común y frecuente. Tanto que las personas nacidas en una cultura a menudo buscan visitar sociedades diferentes a las suyas con el fin de trabajar, estudiar o ejercer algún tipo de influencia en el país extranjero. Asimismo, Church (2010) establece que debido al contacto cultural las locales muestra intereses de comunicación y socialización con los inmigrantes y estudiantes extranjeros. Al mismo tiempo, el autor evidencia que los estudiantes al llegar a una nueva sociedad manifiestan sentimientos de optimismo y entusiasmo. Sin embargo, estos son sustituidos por estrés y ansiedad; en gran parte a causa de los problemas que enfrentan los estudiantes día a día, entre ellos la ubicación, el traslado, el dinero y un ambiente poco familiar. No obstante, una que vez que los estudiantes superan estos problemas, alcanzan nuevamente los sentimientos de seguridad y bienestar en el entorno que se están desenvolviendo.

Hechas las consideraciones anteriores, esta investigación tiene por objetivo determinar la relación entre el contexto cultural y las características de la institución como variables del proceso de aculturación y adaptación cultural en los estudiantes de Educación Superior que realizan una movilidad académica en el extranjero. A través de una metodología mixta con estudios cualitativos y cuantitativos, mediante el uso de entrevistas semiestructuradas a profundidad aplicadas a expertos en temas de internacionalización de la Educación Superior y con la aplicación de encuestas a estudiantes que realizan una movilidad académica al extranjero durante los años 2016-2017. 
Martínez-Lara., S. E., Tamez-González., G. \& Ganga-Contreras., F. A.

Finalmente, los resultados indicaron una relación directa entre el contexto de la cultura y las características de la institución lo cual sirve como apoyo para las Instituciones de Educación Superior para el desarrollo de habilidades de adaptación y facilitar su estancia en el país extranjero.

\section{2.- FUNDAMENTO TEÓRICO}

\section{El contexto cultural como estrategia de aculturación}

De acuerdo con, Kroeber y Kluckhohon (2014) indican que definir el contexto cultural es tratar de dar una definición que tenga múltiples significados. Sin embargo, propone una definición que puede ser utilizada sin importar la localidad. Por lo tanto, contexto cultural es un modo y estilo de vida que tiene un pueblo en, es decir, la manera de pensar, sentir y crear de un grupo de personas en específico. De la misma manera, Geerts (2017) afirma que el contexto cultural puede abarcar dos principales enfoques, el primero desde una realidad mental, mientras que, el segundo, desde un contexto.

Por otro lado, Garay y Fredy (2011) proponen al contexto cultural como un elemento imaginario que delimita una cosa. Dicho de otra manera, un lugar donde todos los individuos de una región comparten la misma cultura, celebran y practican las mismas costumbres y tradiciones, y cuentan con una forma de comunicación común. Asimismo, Forquín (2003) plantea una definición en particular, para el autor contexto cultura es una relación directa entre cultura y conocimiento. En donde, la cultura asume la elaboración de contenidos culturales que a su vez son transmitidos de generación en generación, mientras que, por otra parte, presenta el conflicto de interpretación en relación con la enseñanza y comunicación.

En este mismo orden de ideas, Arango y Buelvas (2016) aseguran que el contexto cultural es todo el entorno físico, donde abarca los ámbitos políticos, históricos y culturales, con la finalidad de establecer un modo común de actuar entre la población. Sin embargo, Unamuno contrasta e incluye un nuevo término, es decir, el contexto cultural forma parte de la diversidad sociocultural y tiene una relación directa con la lingüística. Como sustento a lo anterior, Austin (2019) comenta que el contexto cultural tiene un lazo con lo sociológico, es el total de los conocimientos de una sociedad en que desarrollan, practican y guardan sus conocimientos, por esta razón, García, Hernández y Molina (2014) compone una definición que abarca estas observaciones, donde afirma que el contexto cultural este compuesto por diferentes entornos de los cuales abarca los aspectos sociales, humanos, lenguaje, conducta, política, religión y una forma de convivir en común. 
De acuerdo con Oses (2014) el contexto de la cultura está conformado por cinco aspectos principales, los cuales son: el comportamiento de las relaciones que existen dentro de una cultura; los estilos de comunicación que se implementan más comúnmente; la percepción del espacio personal; las actitudes que se tienen frente al tiempo; y la manera de aprender dentro del mismo contexto cultural. Por tal motivo, el comportamiento dentro del país o zona receptora de cada uno de estos elementos determina el tipo de contexto en el que se desenvolverá el individuo. En relación con lo anterior, existen dos perspectivas que logran encasillar cada zona, país o región refiriéndose al aspecto cultural, mediante un contexto bajo y un contexto alto.

Asimismo, Guzman y Burke (2003) establecieron una taxonomía con ocho factores que brindan herramientas para el desarrollo del proceso de adaptación cultural de acuerdo con el país receptor, es decir, estrategias que ayudan a los estudiantes a poder comprender el funcionamiento de la entidad local. Estos factores abarcan diversas dimensiones que forman parte del proceso de aculturación.

Dicho lo anterior, esto factores son: el interés por temas académicos y no académicos; la importancia de comunicarse con personas de la cultura local, la manera de escribir y uso de la lengua local; la iniciativa para cooperar con otros estudiantes extranjeros; el interés por demostrar esfuerzo en el área académica; mantener la disciplina dentro y fura de la institución; la capacidad para hacer relaciones sociales y personales con personas locales y la capacidad del estudiante por ajustarse a las condiciones generales para vivir en el extranjero. En general, estos factores resultan oportunos debido a la importancia del conocimiento cultural del país receptor que los estudiantes deben de tener previo a realizar una movilidad académica en el extranjero.

Por otra parte, Schweitzer, Buckley y Rossi (2002) presentan una serie de factores premigratorios que presentan los estudiantes internacionales. Dichos factores están relacionados con experiencias traumáticas de acuerdo con situaciones que presentaron las primeras semanas de estancia al país receptor. Es decir, los estudiantes presentan sentimientos de ansiedad, depresión, abuso de sustancias psicoactivas, separación, estrés postraumático y abandono. Igualmente, dichos sentimientos son superados una vez logran adaptarse a la nueva cultura y estilo de vida que tendrán durante su intercambio académico en el extranjero.

Ante esto, para lograr un buen proceso de adaptación cultural en un nuevo país es necesario que los individuos modifiquen sus pensamientos y estén abiertos a tener contacto con una nueva cultura. Es 
decir, que desarrollen diversas habilidades, como escuchar y hablar en un segundo idioma. Asimismo, los individuos deben de presentar un proceso de acuerdo con las necesidades de los inmigrantes, dicho de otra forma, los estudiantes necesitan estar abiertos a las nuevas necesidades que presenten los individuos visitantes. Tales necesidades van relacionadas con el ocio, seguridad física, ámbito laboral y las relaciones interpersonales. Como resultado de estos cambios, se tendría un mejor aprovechamiento y adaptación entre las personas de una cultura diferente, así como con las personas de la cultura de acogida (Ferrer et al., 2014).

Del mismo modo, los estudiantes pueden llegar a presentar otros factores cuando no tienen un buen proceso de adaptación; esto debido a que los estudiantes carecen de la capacidad de afrontar situaciones y problemas. Dicho de otro modo, algunos estudiantes no cuentan con las habilidades y conocimientos para enfrentar diversas situaciones. Los estudiantes necesitan desarrollar estás habilidades previamente a la movilidad o, en el mejor de los casos, durante las primeras semanas de su estancia. Sin embargo, existen casos en que los estudiantes no sabían que contaban con estas habilidades, sobre todo cuando tienen que enfrentarse a costumbres, contextos sociales y ambientes diferentes a los que está acostumbrado a vivir.

En este mismo sentido, Lazarus, Valdés y Folkamn (2016) exponen a la capacidad de afrontamiento como otro factor de una mala adaptación. En tal sentido, la capacidad de afrontamiento es un proceso psicológico que es desarrollado cuando el individuo percibe alguna amenaza. En consecuencia, el afrontamiento corresponde a aquellos esfuerzos conductuales que son desarrollados por el individuo para evitar o reducir situaciones de amenaza o desafío que puedan perjudicar su bienestar. Cabe decir que las diferencias individuales y de personalidad, juegan un rol importante para el desarrollo en el medio social que se desenvolverán y en el país de acogida.

En relación con este último aspecto, Benatuil y Laurita (2010) afirman que la adaptación cultural implica tres aspectos fundamentales, los cuales son enlistados a continuación:

1. Adaptación psicológica: es el nivel de satisfacción y aceptación que el individuo tiene ante el medio cultural nuevo.

2. Aprendizaje cultural: es el desarrollo de habilidades sociales para adaptarse a una cultura. Dicho de otra forma, las competencias que el individuo adquiere al estar en contacto con una cultura diferente a la suya. 
3. Aprendizaje de las conductas adecuadas: principalmente incluye la forma de comportamiento y cumplir con el código de conducta del país anfitrión.

Por tal motivo, los estudiantes que realizan una movilidad académica deberán de contar con conocimientos previos sobre los aspectos culturales, sociales y políticos del país donde realizarán su movilidad académica; esto con la finalidad de poder desarrollar habilidades de interpretación y comunicación con la comunidad local y poder así tener un buen desempeño social y académico.

La importancia de las Instituciones de Educación Superior en el extranjero.

La internacionalización ha evolucionado hacia una estrategia integral (Hudzik, 2008), menciona que las Instituciones de Educación Superior deben de definir claramente sus enfoques y estrategias de internacionalización para sus programas o para su organización y servicio, es por eso importante que se apliquen estrategias dirigidas hacia una nueva generación, a largo plazo, multifuncional que considere las recomendadas por los organismos internacionales y los expertos para que las Instituciones de Educación Superior puedan cumplir con su misión y visión de su razón de ser.

Para entender mejor los términos de internacionalización y globalización de la Instituciones de Educación Superior, se citaron el Marco teórico las opiniones de algunos expertos y de organismos nacionales einternacionales, los cuales exponen sus puntos de vista y sus recomendaciones sobre el tema en particular.

La internacionalidad de Educación Superior es uno de los temas sobresalientes en los últimos años. De acuerdo con, Wit (2011) el tipo de universidad y el modo de operación de la universidad determinará el grado de internacionalidad de la institución. Es así como, el contexto educativo se vuelve un modelo importante de cooperación entre las universidades. Al mismo tiempo, los programas educativos de las múltiples universidades que existen en el mundo determinan a calidad de estudiantes que egresan de las mismas.

Ante esto, las estrategias de internacionalización pueden varían entre una y otra, sin embargo, todos tienen un objetivo en común lograr la internacionalización. Asimismo, es importante mencionar que las realidad y prioridad de las instituciones cambian constantemente; esto debido a diversos factores entre los que destacan: el sistema de gobierno, el crecimiento económico del país, las tecnologías de información, la comunicación entre las diversas autoridades, por mencionar algunas. 
Martínez-Lara., S. E., Tamez-González., G. \& Ganga-Contreras., F. A.

Es así como, Knight (2008) afirma que existen diversos niveles de internacionalidad de acuerdo con las necesidades de cada institución. Por tal motivo, los niveles cambian si lo que se busca es transformar a una institución para que sea más global, más intercultural, y sobre todo con nuevo y mejores métodos de enseñanza. Asimismo, existen otros niveles de internacionalización, como ejemplo cuando se busca que los alumnos que no realizan una movilidad logren obtener un grado internacional. Esto gracias a las acciones por parte de la escuela para ofrecer cursos, talleres o profesores internacionales, también conocido como internacionalización en casa. Por otra parte, la técnica es la más utilizada y son los intercambios académicos al extranjero, los cuales tienen la finalidad de brindar al estudiante la oportunidad de continuar sus estudios en el extranjero, al mismo tiempo, brinda nuevas técnicas de enseñanza y conocimiento de nuevas personas e intercambio de ideas entre alumnos y profesores de diferentes países.

\section{Modelos académicos relacionados con la movilidad estudiantil}

De acuerdo con, Arteaga y Cruz (2016) indican que las universidades tienen como finalidad la creación de nuevo conocimiento, nuevas ideas y nuevos métodos de aprendizaje. De igual manera, las instituciones de Educación Superior demuestran un gran interés por crear redes de conocimiento entre los ámbitos de investigación, docencia y estudio. Por otra parte, Casanova (2016) menciona que una institución de Educación Superior tiene por objetivo la creación y producción del conocimiento. Es decir, realizar difusión del conocimiento y la cultura. Sin embargo, Almarcha (2001) ve a las instituciones de Educación Superior como un factor directo del desarrollo económico y social. Es decir, un país que cuenta con universidades de prestigio tiende a tener una población preparada y dispuesta aprovechar los recursos para mejorar las condiciones y calidad de vida.

Ante esto, Van der Molen (1999) menciona que, debido al desarrollo de múltiples modelos a lo largo de la historia, las instituciones de Educación Superior adoptan experiencias que sirven como guía entre las universidades. Dicho de otra manera, las instituciones de Educación Superior crean modelos que pueden servir como base para otras instituciones en diferentes países. Como resultado de esto, los modelos educativos son aplicados en diferentes partes del mundo adaptándose a las necesidades de cada uno. Por tal motivo, una de las siguientes demandas en las universidades es proporcionar una educación de calidad. Por consecuencia, la educación superior tiene por objetivo la formación de personas con competencias de aprendizaje autónomo y a su vez de conocimiento que le permita al estudiante desarrollarse en los ámbitos laboral, personal y académico. 
En tal sentido, Cruz y Cruz (2008) analizan a la Educación Superior como una promotora de desarrollo, democracia y convivencia. Así como también, la Educación Superior debe ser flexible y diversificada en los diferentes programas educativos con los que cuenta. Al mismo tiempo, la Educación Superior ofrece posibilidades de crecimiento en los ámbitos, laborales, personales y sociales. Dicho de otra forma, la Educación Superior ofrece el desarrollo de capacidades para laborar dentro y fuera de la institución y aptitudes sociales que ayuden a tener una mejor convivencia con los demás.

Asimismo, las instituciones de Educación superior otorgan una formación de calidad académica. A través de diferentes métodos de enseñanza, los cuales son factores fundamentales para el éxito o fracaso de esta. Es decir, una universidad que cuenta con un modelo educativo de calidad tiene con finalidad de que sus estudiantes serán personas preparadas y capaces de desarrollarse en el mundo laboral internacional. Esto, debido al aprendizaje y conocimiento adquirido durante su formación.

Finalmente, las características de la institución para esta investigación son todos aquellos programas de calidad con las que cuentan las instituciones de Educación Superior. Es decir, los programas académicos, vinculación internacional, calidad de los profesores, oportunidades de servicio y prácticas profesionales. En suma, una educación brinda a los estudiantes oportunidades de aprendizaje académico, social y cultural que brinda una universidad en específico.

\section{3.-MÉTODO}

\section{Diseño}

De acuerdo con, Creswell y Miller (2000) una investigación cualitativa tiene como finalidad investigar las experiencias vividas de un grupo de individuos, a través, de la recopilación de datos no estructurados obtenidos de realizar entrevistas a profundidad. Como resultado, el investigador puede comprender e interpretar el significado de la información recopilada donde el grado de confiabilidad y autenticidad de los datos es considerablemente alto.

Asimismo, Cadena et al (2017) indican que los métodos cuantitativos tienen una precisión para los procedimientos de medición a través de la selección subjetiva de indicadores. Es decir, utiliza la selección de conceptos también llamadas variables de medición. Las variables son aquellos conceptos que cumplen con ciertas características y cuenten con dos o más atributos de un evento en especial (Herrera et al, 2016).

8 Revista Política, Globalidad y Ciudadanía | Vol. 7, Núm. 14, junio - diciembre 2021 | ISSN 2395-8448 | http://revpoliticas.uanl.mx/ 
Martínez-Lara., S. E., Tamez-González., G. \& Ganga-Contreras., F. A.

En consecuencia, las variables cuentan con diferentes formas de medición, dicho de otra manera, la forma en que un valor o una categoría le es asignado a una variable es conocido como medición. De acuerdo con, World Bank (2003) la investigación cuantitativa brinda datos de calidad que ayudan a la formulación de hipótesis, refuerza el diseño del cuestionario y amplía las conclusiones de la investigación. En este sentido, la hipótesis representa una posibilidad de comprobar lo planteado, es decir, la posibilidad de afirmar la existencia o la inexistencia de un fenómeno. Asimismo, la hipótesis mantiene una relación directa con el objetivo del estudio de la investigación (Inche et al, 2003). Ante esto, se plantea las siguientes hipótesis de investigación:

$H_{1}$ : El contexto cultural se relaciona de una manera positiva con el proceso de aculturación.

$H_{2}$ : Las características de la institución se relacionan de una manera positiva con el proceso de aculturación.

\section{Participantes}

En primera instancia, se procedió con las entrevistas a profundidad a expertos en material de internacionalización de la Educación Superior, en donde fueron contactados seis expertos de diversas universidades. En primer lugar, fue seleccionado un experto de la Universidad Autónoma de Nuevo León (UANL). En segundo lugar, fueron elegidos dos expertos procedentes la Universidad de Monterrey (UDEM). En tercer lugar, fueron seleccionados a tres expertos extranjeros procedentes de la Universidad

de Santo Tomás en Chile, la Universidad de la Guajira en Colombia y la Universidad Autónoma de Barcelona en España.

Posteriormente, las encuestas fueron aplicadas a 43 estudiantes de la Universidad Autónoma de Nuevo León que realizaron un intercambio académico durante el periodo de 2016-2017. La tabla 1 muestra el perfil del encuestado. 
Tabla 1: Perfil del encuestado.

\begin{tabular}{lcl}
\hline Variables & Frecuencia & Porcentaje \\
\hline Género & 17 & $40 \%$ \\
Masculino & 26 & $60 \%$ \\
Femenino & & \\
Edad & 34 & $79 \%$ \\
20 a 23 años & 05 & $12 \%$ \\
24 a 27 años & 04 & $09 \%$ \\
28 a 31 años & & \\
País & 18 & $42 \%$ \\
España & 07 & $16 \%$ \\
Francia & 06 & $14 \%$ \\
Chile & 03 & $07 \%$ \\
Colombia & 09 & $21 \%$ \\
Otros & & \\
\hline
\end{tabular}

Fuente: Elaboración propia (2021).

\section{Instrumentos}

El instrumento de medición para la metodología cualitativa fue realizado a través de una búsqueda de literatura en aquellas investigaciones en las que el tema principal fueran los siguientes temas: migración, movilidad académica, proceso de aculturación, modelos de aculturación, teorías sobre adaptación cultural, de los cuales destacan Austin (2019), Avendaño (2016), Benatuil et al (2016), Cruz et al (2008), Enríquez (2007), Fiocchi (2015), Granada (2003). Por su parte, los estudios encontrados mostraron una relación con diversos conceptos que son utilizados para la aculturación. Es decir, en su mayoría la aculturación cuenta con vínculo directo con la cultura, la institución, el contexto cultura y las aptitudes y capacidad con los que cuentan los estudiantes para realizar un intercambio al extranjero. Dicho lo anterior, se creó un guion de la entrevista conformado por un total 31 preguntas divididas por las dimensiones de estudio que son contexto cultural y características institucionales.

Ahora bien, para el instrumento cuantitativo la encuesta quedó estructurada por 30 preguntas divididas de la siguiente manera: 4 ítems para los datos generales, 9 ítems para la variable contexto cultural y 17 ítems para la variable de características de la institución, información que fue recolectada de las investigaciones de Díaz et al (2013), Gaxiola et al (2011), Peralta et al (2006), Peña (2009), Salgado 
Martínez-Lara., S. E., Tamez-González., G. \& Ganga-Contreras., F. A.

et al, (2012), por mencionar algunos. Asimismo, la encuesta utilizó una escala de medición tipo Likert en donde 1 es "nada importante" y 5 "muy importante".

\section{Procedimiento}

En relación con lo que se ha presentado durante esta investigación, se presenta un marco referencial en apoyo a los procesos de aculturación y estrategias de aculturación que facilidad la adaptación cultural a las personas que motivos académicos o laborales cambian su lugar de residencia por un tiempo determinado. Ante esto, y para fines de esta investigación las variables establecidas son contexto cultural y características de la institución, mismas que sirvieron de referencia para la elaboración de los instrumentos de medición.

Por su parte, las entrevistas a profundidad fueron aplicadas durante los meses de septiembre a octubre del 2020, mientras que las encuestas a estudiantes se aplicaron durante los meses de septiembre a noviembre 2020; ambos instrumentos fueron aplicados de manera electrónica a través de un formulario en Google Forms.

Posteriormente, el análisis de resultados fue realizado mediante el uso de diversos softwares como lo es NVivo para los datos cualitativos, con el uso de la categorización e presentación de la información, mientras que, los datos cuantitativos fueron analizados en IBM SPSS con los cálculos estadísticos de Alfa de Cronbach, media, desviación estándar y correlaciones.

\section{4.- RESULTADOS}

De acuerdo con, Serrano (2013) menciona que la codificación es una técnica para analizar los datos que han sido recolectados para su respectivo análisis. Para, Strauss y Corbin (2008) la codificación son los nombres que el investigador establece a los conceptos derivados de la codificación. Sin embargo, Monge (2015) afirma que la codificación es un proceso de análisis y conceptualización el cual requiere de un talento especial.

Ante esto, los datos obtenidos en las entrevistas a profundidad fueron codificados para conocer su categorización y palabra asociada en el marco de las variables de investigación. La tabla 2 muestra la codificación del estudio. 
Tabla 2: Codificación del estudio.

\begin{tabular}{|c|c|c|c|}
\hline Clave & Factor & Categoría & Palabra asociada \\
\hline \multirow[t]{3}{*}{$\mathrm{CA}$} & \multirow[t]{3}{*}{$\begin{array}{l}\text { Características } \\
\text { alumno }\end{array}$} & Situación personal & $\begin{array}{l}\text { Apego familiar, estado civil, apoyo general, fácil } \\
\text { psicológico, ingresos personales, edad, género, } \\
\text { continuidad, emociones. }\end{array}$ \\
\hline & & Aptitudes & $\begin{array}{l}\text { Sociable, dedicado, responsable, dependencia, } \\
\text { administración de necesidades, honestidad, alegría, } \\
\text { respeto, empático, }\end{array}$ \\
\hline & & Estilo & $\begin{array}{l}\text { Vestimenta, aventurero, estatus social, emociones, } \\
\text { redes sociales, edad, compañía, arriesgado, } \\
\text { responsable, seguridad }\end{array}$ \\
\hline \multirow[t]{2}{*}{ ID } & \multirow[t]{6}{*}{ Idioma } & Conocimiento & Dominio. \\
\hline & & Uso & $\begin{array}{l}\text { Practica e interacción, historial, educación, } \\
\text { aprendizaje }\end{array}$ \\
\hline \multirow[t]{7}{*}{$\mathrm{AC}$} & & Características de la persona & Introvertida, observación. \\
\hline & & Tipología de adaptación & Separación, adaptación, integración, combinación \\
\hline & & \multirow{2}{*}{$\begin{array}{l}\text { Estrategias } \\
\text { Conocimientos previos }\end{array}$} & Convivencia, contacto, comunicación y amistad \\
\hline & & & $\begin{array}{l}\text { comunicación, referencias, conocimiento, código de } \\
\text { conducta }\end{array}$ \\
\hline & \multirow[t]{3}{*}{ Aculturación } & $\begin{array}{l}\text { Mecanismos Favorables } \\
\text { de }\end{array}$ & $\begin{array}{l}\text { Aprendizaje intercultural, enriquecimiento, entorno, } \\
\text { independencia, comunicación, tradiciones, ayuda. }\end{array}$ \\
\hline & & aculturación & Religión, limitador, competencias, etnocéntrica. \\
\hline & & Continuidades contextuales & $\begin{array}{l}\text { Características, aspectos generales, vital, similitud y } \\
\text { diferencias. }\end{array}$ \\
\hline \multirow[t]{3}{*}{ IS } & \multirow[t]{3}{*}{ Institución } & Recursos & $\begin{array}{l}\text { Infraestructura, tecnología, recursos (financiero), } \\
\text { cafetería, maestros. }\end{array}$ \\
\hline & & Condiciones internas & Maestros, programas educativos, acceso, ambiente. \\
\hline & & Tiempo & Duración del curso. \\
\hline DPA & $\begin{array}{l}\text { Desarrollo } \\
\text { personal } \\
\text { académico }\end{array}$ & Beneficios & $\begin{array}{l}\text { Trabajo en equipo, tolerancia e independencia. } \\
\text { Prestigio, internacionalización }\end{array}$ \\
\hline $\mathrm{CCA}$ & $\begin{array}{l}\text { Choque cultural } \\
\text { académico }\end{array}$ & Efecto & $\begin{array}{l}\text { Aislamiento. } \\
\text { Estrés, incertidumbre y retorno anticipado }\end{array}$ \\
\hline
\end{tabular}

Fuente: Elaboración propia (2021). 
Martínez-Lara., S. E., Tamez-González., G. \& Ganga-Contreras., F. A.

Posteriormente, los resultados obtenidos fueron agrupados por factor y redactados con las respuestas obtenidas por parte de los expertos. A continuación, son mostrados los resultados obtenidos de las entrevistas a profundidad.

Factor $\mathrm{x}_{1}$ Contexto de la otra cultura: en general todos los entrevistados, por un lado, señalan que es recomendable que los estudiantes conozcan y entiendan las características culturales del país al que van a ir, mientras que, por otro lado, señalan que no debería de existir similitud entre la cultura receptora y la cultura de origen. Puesto que, el intercambio brinda la experiencia de reconocer las diferencias culturales. Es decir, el estudiante logra obtener una visión global y empieza a entender a aquel que es diferente a él. Dando como resultado que la experiencia del intercambio resulte ser mas enriquecedora.

Factor $\mathrm{x}_{2}$ Características de la institución: para los expertos el tema fundamental es que los estudiantes deben de empezar a familiarizarse con la institución, mediante un curso de inducción. Dicho de otra manera, la institución debe de realizar un curso para aquellos estudiantes extranjeros donde se les enseñe un mapa de la universidad, área de salones, biblioteca, laboratorios, comedor, administración para lograr así que los estudiantes se empiecen a familiarizar. Vale destacar, que los seis expertos coinciden en que la comunicación profesor alumno es importante para su orientación y tutoría. Sin embargo, mencionan que esto únicamente se presenta en aquellas culturas con son similares a las de México. Ahora bien, los estudiantes deben de tener el conocimiento de cuál es el plan de estudio que maneja la universidad en la que realizarán la movilidad. Asimismo, la selección de las asignaturas que llevará a lo largo del curso para poder así presentar un buen aprovechamiento académico. Otro punto es, los días feriados ayudan al estudiante para aprender más acerca de la cultura, inclusive para realizar algún viaje a alguna ciudad cercana. Así como también, el tiempo de duración del curso dependerá del proceso de adaptación. Los expertos a quienes se les hicieron la entrevista consideran que para que exista un proceso de adaptación necesita el curso ser mayor a los cuatro meses de estadía.

Factor $\mathrm{x}_{3}$ Estrategias de aculturación: la información obtenida por parte de los expertos es que para los estudiantes es conveniente conservar las costumbres de su país de origen. Sin embargo, necesitan estar abiertos a aprender de las costumbres que ofrece el país. Es decir, los estudiantes tienen que estar dispuestos a querer adaptar su comportamiento de acuerdo con la situación cultural que se le esté presentando sin atentar contra sus propios conceptos o marcos de referencia. Ahora bien, los expertos realizan una lista de problemáticas que enfrenta un estudiante durante su movilidad las cuales son: organización de tiempo, adaptación al sistema educativo, adaptación a costumbres y tradiciones, 
problemas académicos, problemas de seguridad, organización del presupuesto mensual, problemas de transporte o traslados, revalidación de créditos. Como resultado a esto, existen ciertos estudiantes que presentan una actitud de aislamiento. Por tal motivo, los expertos señalan que esto se debe principalmente a que el estudiante no estaba preparado para realizar la movilidad. Es por esa razón que, los estudiantes necesitan una preparación previa donde puedan escuchar recomendaciones que les sirvan al momento de encontrarse de movilidad.

Factor $\mathrm{x}_{4}$ Aculturación: los expertos señalan ciertos factores que les puede ayudar a los estudiantes a presentar un buen proceso de adaptación. Dichos factores son: preparación previa, actitud del estudiante, actitud de apertura, actitud de la universidad de acogida, buena actitud por parte de los alumnos receptores, contar con un tutor, tener asesoría por parte de las universidades tanto receptora como de origen y finalmente que el alumno vaya convencido de querer realizar un intercambio. Asimismo, los expertos describen un perfil ideal de un estudiante que realice un intercambio el cual es: una persona con interés y curiosidad por aprender cosas nuevas, aquella persona que es capaz de observar lo que pasa a su alrededor, una persona que muestre empatía, tolerancia y respeto por aquel que es diferente, una persona que sea autónoma e independiente, responsable y que cuente con los requisitos académicos solicitados por parte de la institución.

Posteriormente, los datos cuantitativos fueron procesados bajo las pruebas estadísticas Alfa de Cronbach y estadísticos descriptivos. De acuerdo con, Cortina (1993) menciona que la descripción del alfa es la función de la medida en que los elementos o ítems de una prueba tienen comunalidades elevadas y, por lo tanto, unicidad baja. Es decir, un alfa alta no significa unidimensionalidad. Sin embargo, cada vez que los ítems tengan comunalidades altas el alfa será alta, específicamente cuando el factor cuenta con un gran número de elementos o ítems.

Asimismo, Cozby (2005) ha demostrado que un alfa mayor a 0.9 puede considerarse sospechosos debido a que los resultados tienden a mostrar bajas intercorrelaciones. Por tal motivo, los autores proponen que los valores aceptados no deberán ser menores de 0.50 y 0.60 para demostrar que los ítems tienen confiabilidad.

En relación con lo anterior, el análisis fue realizado, en donde las variable contexto de la cultura mostró un resultado significativo para la investigación al obtener un a =.789, mientras que la variable características de la institución las pruebas arrojaron un a=.813; lo que significa que ambas variables 
Martínez-Lara., S. E., Tamez-González., G. \& Ganga-Contreras., F. A.

juegan un papel importante dentro del proceso de aculturación, es decir, aquellos estudiantes que realicen un intercambio académico deben prestar atención en aspectos relacionados con los mismo. Por su parte, la tabla 3 muestra los resultados del alfa.

Tabla 3: Alfa de Cronbach de las variables de investigación

\begin{tabular}{llll}
\hline Constructo & $\begin{array}{l}\text { Estadística de fiabilidad } \\
\text { Alfa de Cronbach }\end{array}$ & Elementos & Confiabilidad \\
& .789 & 10 & \\
\hline Contexto de la cultura & .813 & 16 & Aceptada \\
Características de la institución & Aceptada \\
\hline
\end{tabular}

Fuente: Elaboración propia. Datos: Datos obtenidos IBM SPSS.

Posteriormente, fueron realizados el análisis de estadísticos descriptivos para cada una de las variables de investigación. Para la variable contexto de la cultura se incluyeron ítems que midieran la similitud entre las estructuras familiares, la religión como un factor que influye para realizar una movilidad, la manera de comunicación de la cultura receptora, la calidad y uso del servicio del transporte público, así como también, el grado de dificultad para comprender a la cultura receptora, e inclusive que el estudiante busque adaptar hábitos de la cultura como propios.

Como resultado del análisis de los estadísticos descriptivos, los datos arrojaron que la calidad y uso del servicio del transporte público de la ciudad es el indicador con mayor importancia $(M=4.61, D E$ $=.859)$. Por su parte, que el estudiante se sienta cómodo con la cultura receptora presentó niveles altos por arriba de la media teórica $(M=4.49, D E=.669)$. En lo que se refiere al indicador si la cultura receptora tiende a ser sociable los resultados indicaron niveles altos $(M=3.84, D E=.954)$. Por otro lado, el indicador que el estudiante adapte hábitos de la cultura receptora como propios presentó de igual manera niveles altos $(M=3.72, D E=.966)$. Asimismo, el indicador que mide la similitud entre las estructuras familiares mostró niveles altos por arriba de la media teórica $(M=2.88, D E=1.090)$. En lo que se refiere al indicador sobre la religión como factor que influye para realizar una movilidad, los resultados arrojaron exactamente la media teórica $(M=2.50, D E=1.195)$, lo que significa que los estudiantes toman en cuenta el tipo de transporte que van a utilizar durante su movilidad debido a que pueden presentar sentimientos de angustia, así como lo que menos toman en cuenta es la relación con la estructura familiar, debido a que el estudiante busca conocer y experimentar cosas nuevas.

Finalmente, los indicadores del tipo/estilo de vestimenta de la cultura receptora y el grado de dificultad para comprender a la cultura receptora mostraron resultados por debajo de la media teórica $(M$ 
$=2.44, D E=2.37)$, respectivamente. Esto resulta llamativo debido a que para el estudiante es importante que la ciudad donde realizará su movilidad cuenta con servicio de calidad para utilizar el transporte público. Por su parte, la tabla 4 muestra el resultado del análisis de los estadísticos descriptivos de la variable contexto de la cultura.

Tabla 4: Estadísticos descriptivos variable contexto de la cultura

\begin{tabular}{|c|c|c|c|c|c|}
\hline ítems & Mín. & Máx. & M & DE & $\%$ \\
\hline Estilos de aprendizaje que brinda la institución receptora & 1 & 5 & 4.48 & 0.728 & 60.2 \\
\hline Calidad de los profesores & 2 & 5 & 4.7 & 0.564 & 74.4 \\
\hline Facilidad para realizar los trámites académicos en la institución receptora & 1 & 5 & 4.69 & 0.629 & 76.3 \\
\hline Actividades de bienvenida a los estudiantes extranjeros & 1 & 5 & 4.03 & 1.097 & 44 \\
\hline Apoyo brindado por parte de la institución hacia los estudiantes extranjeros & 2 & 5 & 4.73 & 0.571 & 78.2 \\
\hline Instalaciones de la universidad receptora & 1 & 5 & 4.14 & 0.877 & 40.6 \\
\hline Duración del curso & 1 & 5 & 4.26 & 0.945 & 51.9 \\
\hline Estándares de admisión & 1 & 5 & 4.21 & 0.882 & 45.9 \\
\hline Proceso de revalidación de las materias & 1 & 5 & 4.73 & 0.622 & 80.1 \\
\hline
\end{tabular}

Fuente: Elaboración propia (2021). Datos: Datos obtenidos de SPSS. N = 266. Media teórica = 3.

Es así como, la variable contexto de la cultura explica las características que los estudiantes buscan y deben conocer del país en donde realizarán la movilidad. Así mismo, los estudiantes aseguran que el uso del transporte público de la ciudad es una característica fundamental para lograr un buen proceso de adaptación. Por lo contrario, el tema de la religión que se practica en el país receptor resulta ser una característica que los estudiantes no toman con mucha importancia al momento de realizar una movilidad académica.

Por su parte, la variable característica de la institución (ver tabla 5) busca conocer cuáles son las características que debe de tener la institución receptora para poder realizar su movilidad académica. Ante esto los resultados mostraron niveles por arriba de la media teórica. Se puede observar características significativas como lo son el proceso de revalidación $(M=4.73, D E=.622)$, el apoyo brindado por parte de la institución hacia los estudiantes extranjeros $(M=4.73, D E=.571)$, la calidad de los profesores $(M=4.70, D E=.564)$, la facilidad para realizar los trámites académicos en la institución receptora $(M=4.69, D E=.629)$, los estilos de aprendizaje que brinda la institución receptora $(M=4.48$, 
Martínez-Lara., S. E., Tamez-González., G. \& Ganga-Contreras., F. A.

$D E=.728)$, la duración del curso $(M=4.26, D E=.945)$, los estándares de admisión $(M=4.21, D E=$ $.882)$, las instalaciones de la universidad receptora $(M=4.14, D E=.877) \mathrm{y}$ las actividades de bienvenida a los estudiantes extranjeros $(M=4.03, D E=1.097)$, lo que significa que los estudiantes buscan que el proceso de revalidación sea claro y lo más directo posible para evitar así algún inconveniente con sus trámites administrativos y que estos puedan perjudicar su desempeño académico durante su movilidad.

Tabla 5: Estadísticos descriptivos variable características de la institución

\begin{tabular}{lccccc}
\hline ítems & Mín. & Máx. & M & DE & $\%$ \\
\hline Estilos de aprendizaje que brinda la institución receptora & 1 & 5 & 4.48 & 0.728 & 60.2 \\
Calidad de los profesores & 2 & 5 & 4.7 & 0.564 & 74.4 \\
Facilidad para realizar los trámites académicos en la institución receptora & 1 & 5 & 4.69 & 0.629 & 76.3 \\
Actividades de bienvenida a los estudiantes extranjeros & 1 & 5 & 4.03 & 1.097 & 44 \\
Apoyo brindado por parte de la institución hacia los estudiantes extranjeros & 2 & 5 & 4.73 & 0.571 & 78.2 \\
Instalaciones de la universidad receptora & 1 & 5 & $\mathbf{4 . 1 4}$ & $\mathbf{0 . 8 7 7}$ & $\mathbf{4 0 . 6}$ \\
Duración del curso & 1 & 5 & 4.26 & 0.945 & 51.9 \\
Estándares de admisión & & & & & \\
Proceso de revalidación de las materias & 1 & 5 & 4.21 & 0.882 & 45.9 \\
\hline
\end{tabular}

Fuente: Elaboración propia (2021). Datos: Datos obtenidos de SPSS. N=266. Media teórica = 3

Por lo tanto, la variable característica de la institución afirma que los estudiantes buscan que durante el proceso de revalidación de materias cuenten con el apoyo por parte de la universidad, con la finalidad de no presentar problemas durante el proceso y puedan continuar con sus estudiantes. Sin embargo, los estudiantes no prestan mayor importancia a las instalaciones de la universidad debido a que buscan conocer y desarrollarse en un ambiente nuevo.

Con lo anterior expuesto, se Comprueba la hipótesis formulada para esta investigación, en donde se encuentra una relación positiva entre el contexto cultural con el proceso de aculturación, esto debido a que los estudiantes buscan una relación relativa entre la cultura de origen y la receptora, así como tener lo mayores conocimientos previos posibles, con la finalidad de lograr una integración y comprensión del estilo de vida de la ciudad donde se realizará la movilidad.

$H_{1}$ : El contexto cultural se relaciona de una manera positiva con el proceso de aculturación. 
Posteriormente, la hipótesis dos se comprueba esto debido a que se muestra una relación positiva entre las características de la institución y el proceso de aculturación, lo que significa que los estudiantes al momento de llegar a la institución extranjera buscan tener los conocimientos necesarios para realizar su movilidad, tales como: procesos administrativos, ubicación, recorrido por las instalaciones, profesores, oferta educativa, programas, actividades extracurriculares.

$\mathrm{H}_{2}$ : Las características de la institución se relacionan de una manera positiva con el proceso

\section{5.- CONCLUSIONES}

La movilidad académica resulta un factor importante para que los estudiantes, profesores e investigadores obtengan un intercambio de ideas y conocimiento con personas de otras culturas, con la finalidad, de conocer y aprender diferentes técnicas de aprendizaje. Es así como, esta investigación presentó un análisis sobre la relación entre el contexto cultural y las características de la institución como estrategias de aculturación, específicamente, en los estudiantes de Educación Superior de la Universidad Autónoma de Nuevo León que realizaron un intercambio académico al extranjero, debido a que se busca contribuir en la creación de modelos de aculturación que sean de libre uso tanto para estudiantes como para las Instituciones de Educación Superior en apoyo a fomentar la movilidad entre sus estudiantes y profesores.

Con respecto al contexto cultural, se concluye que es recomendable que los estudiantes conozcan y entiendan las características culturales del país receptor, así como motivar a los estudiantes a buscar instituciones educativas donde no exista una similitud cultural y educativa, esto con la finalidad de ampliar sus conocimientos y poder así poner en práctica las técnicas interculturales y de aculturación de los estudiantes.

Por otra parte, las características de la institución juegan un papel fundamental para el desempeño académico el estudiante, en donde la inducción es importante para los estudiantes extranjeros, así como brindar el conocimiento académico y la ubicación de las instalaciones de esta; es decir, conocer sobre los planes de estudio, la oferta de unidades de aprendizaje y la duración de ciclo académico.

Ante esto, es importante realizar propuestas de modelos que ayuden a establecer las estrategias de aculturación útiles para los estudiantes que realicen una movilidad, así como poder brindar información de calidad acerca de las diversas problemáticas que los estudiantes pueden al momento de llegar al país receptor.

18 Revista Política, Globalidad y Ciudadanía | Vol. 7, Núm. 14, junio - diciembre 2021 | ISSN 2395-8448 | http://revpoliticas.uanl.mx/ 
Martínez-Lara., S. E., Tamez-González., G. \& Ganga-Contreras., F. A.

Asimismo, como futuras investigación se propone realizar estudios en donde se tome en cuenta el país receptor y poder así establecer un perfil de aculturación de acuerdo con la región geografía donde el estudiante realice su movilidad académica, esto con la finalidad de poder ayudar a los estudiantes y las Instituciones de Educación Superior a incrementar su movilidad académica.

Finalmente, se contesta de una manera positiva la interrogante de investigación en donde el contexto cultural y las características de la institución se relacionan positivamente con el proceso de aculturación en estudiantes.

\section{REFERENCIAS.}

Almarcha, A. (2001). Misión de la universidad. Enseñanza superior competitiva: la globalización de los mercados Reis. Revista Española de Investigaciones Sociológicas, (93), 205-220.

Austin, T.R. (20 mayo 2019). Para comprender el concepto de cultura. Recuperado de: http://www.estudiosindigenas.cl/educacion/compcult.pdf

Arango, L., y Buelvas, J. (2016). Contexto cultural, Etnolinguística, y Sociodemográfico en América Latina. Caso Ecuador, Costa Rica, Perú y Colombia. Omnia, 22(2), 119-128.

Arteaga, M., y Cruz, M. (2016). Reseña de "Las universidades modernas: espacios de investigación y docencia”. De Burton R. Clark, (84).

Austin, T.R. (20 mayo 2019). Para comprender el concepto de cultura. http://www.estudiosindigenas.cl/educacion/compcult.pdf

Avendaño, W. R., Guacaneme, R. E. (2016). Educación y globalización: una visión crítica. Civilizar Ciencias Sociales y Humanas, 16(30), 191-206.

Benatuil, D., y Laurito, J. (2016). La adaptación cultural en estudiantes extranjeros. Psicodebate. Psicología, Cultura y Sociedad, 10, 119-134.

Cadena, P., Rendón, R., Aguilar, J., Salinas, E., De la Cruz, F., y Sangerman, D. (2017). Métodos cuantitativos, métodos cualitativos o su combinación en la investigación: un acercamiento en las ciencias sociales. Revista Mexicana de Ciencias Agrícolas, 8(7), 1603-1617.

Casanova, H. (2016). Modelos universitarios emergentes. Universidades, (67), 4-5.

Church, A. (2010). Sojourner adjustment. Psychological Bulletin, 91(3), 540-572.

Cortina, J. M. (1993). Whats is coefficient alpha? An examination of theory and applications. The Jorunal of Applied Psychology, 78(1), 98-104.

Cozby, P. C. (2005). Métodos de Investigación del Comportamiento. McGraw Hill. 
Cruz, Y., y Cruz, A. K. (2008). La Educación Superior en México. Tendencias y desafíos. Avaliação: Revista da Avaliação da Educação Superior, 13(2), 293-311.

Díaz, A. (2013). Intercultural understanding and profesional learning through critical engagement. Babel, 48(1), pp-12-19

Enríquez, Á. (2007). La significación en la cultura: concepto base para el aprendizaje organizacional. Universitas Psychologica, 6(1), 155-162.

Ferrer, N., Connell, J., y Travaglione, A. (2004). Co-worker trust as a social catalyst for constructive employee attitudes. Journal of Managerial Psychology, 19(6), 608-622.

Fiocchi, M.C., y Rojas, H. (2015). La experiencia de intercambio estudiantil en el extranjero: Análisis de las percepciones de chilenos que en su adolescencia participaron en programas de youth for understanding. Ultima década, 23(43), 207-233

Forquin, J.C. (2002). Escola e cultura: as bases sociais e espistemológicas do conhecimiento escolar. Ed. Artes.

Garay, G., y Fredy, R. (2011). Perspectivas de historia y contexto cultural en la enseñanza de las ciencias: discusiones para los procesos de enseñanza y aprendizaje. Ciencia y Educación (Bauru), 17(1), 51-62.

García, F., Alfaro, A., Hernández, A., y Molina, M. (2006). Diseño de Cuestionarios para la recogida de información: metodología y limitaciones. Revista Clínica de Medicina de Familia, 1(5), 232-236.

Gaxiola, J.C., González, S., y Gaxiola, E. (2011). Autorregulación, Resiliencia y Metas Educativas: Variables Protectoras del Rendimiento Académico de Bachilleres. Revista Colombiana de Psicología, 22(2). pp 241-252.

Geertz, C. (2017). The Interpretation of Cultures. Basic Books.

Granada, H. (2003). La cultura como estrategia de adaptación en la interacción sujeto social ambiente. Investigación \& Desarrollo, 11(1), 134-161.

Guzman, E. y Burke, M. (2003). Development and test of an international student performance taxonomy. International Journal of Intercultural Relations, 27(6), 659-681.

Herrera, H., Cuesta, A., y Escalante, J. E. (2016). El concepto de variable: un análisis con estudiantes de bachillerato. Educación Matemática, 28(3), 217-240.

Inche, J., Andía, Y., Huamanchumo, H., López, M., y Vizcarra, J. (2003). Paradigma cuantitativo: un enfoque empírico y analítico. Industrial Data, 6(1), 23-37.

Knight, J. (2008). Higher Education in Turmoil. The Changing World of Internationalization. Sense Publishers. 
Martínez-Lara., S. E., Tamez-González., G. \& Ganga-Contreras., F. A.

Kroeber, L., y Kluckhohon, C. (2014). Cultura: una revisión crítica de conceptos y definiciones. Papers of the Peabody Museum of American Archeology and Ethnology, 47(1), 270-285.

Lazarus, R., Valdés, M., y Folkman, S. (1986). Estrés y procesos cognitivos. Ediciones Martínez Roca.

Monge, V. (2015). La codificación en el método de investigación de la grounded theory o teoría fundamentada. Innovaciones educativas, (22), 77-84.

Oses, P. (2014). Análisis de los factores que facilitan o dificultan a adaptación de los estudiantes de intercambio en la Facultad de Economía y Negocios de la Universidad de Chile (Tesis de pregado, Universidad de Chile). Archivo digital. http://repositorio.uchile.cl/handle/2250/115363

Peña, L., y Bravo, E. (2002). Globalización y educación. Educere, 6(19), 283-288.

Peralta, F., y Arellano, A. (2006). La autodeterminación de las personas con discapacidad intelectual: situación actual en España. CES Psicología, 7(2). pp-59-77

Salgado, J.F., y Cabal, A.L. (2012). Evaluación del Desempeño en la Administración Pública del Principado de Austrias: Análisis de las Propiedades Psicométricas. Revista de Psicología del Trabajo y de las Organizaciones, 27(2). pp 75-91.

Schweitzer, R., Buckley, L., y Rossi, D. (2002). The psychological treatment of refugees and asylum seekers: what does the literature tell us? Most Pluriels, (21), 1-37.

Serrano, J. (2013). Respuestas múltiples en la investigación educativa: codificación, tabulación y análisis. Revista de Investigación Educativa, 31(2), 361-374.

Strauss, A., y Corbin, J. M. (2008). Basic of qualitative research 3ra edición. Sage Publications.

Van Der Molen, H.J. (1999). Metas y proyectos de la educación superior. Fundación UniversidadEmpresa.

Ward, C., Bochner, S., y Furnham, A, (2001). The Psychology of culture shock. Routledge.

Wit, H. (2011). Globalización e internacionalización de la educación superior. RUSC. Universities and Knowledge Society Journal, 8(2), 77-84.

World Bank (23 mayo 2019). Empowerment and proverty reduction: evaluation team. World development report 2000/200. www.worldbank.org/ 